\title{
Risk factors for repeated cerebrospinal shunt failures in pediatric patients with hydrocephalus
}

Sagun Tuli, M.D., James Drake, M.B.B.Ch., F.R.C.S.(C.), Jerry Lawless, B.Sc., M.Sc., Ph.D., Melanie Wigg, B.A., M.Math., M.Sc., and Maria Lamberti-Pasculli, R.N.

Division of Neurosurgery, The Hospital for Sick Children, Toronto, Ontario, Canada; and Department of Statistics and Actuarial Science, University of Waterloo, Waterloo, Canada

Repeated cerebrospinal fluid (CSF) shunt failures in pediatric patients who have undergone neurosurgical procedures are common, and they are a significant cause of morbidity and occasionally mortality. To date, the risk factors for repeated failure have not been established. By performing survival analysis for repeated events, the authors examined the effects of patient characteristics, shunt hardware, and surgical details in a large cohort of patients.

During a 10-year period all pediatric patients with hydrocephalus requiring CSF diversionary procedures were included in a prospective single-institution observational study. Patient characteristics were defined as age, gender, weight, head circumference; American Society of Anesthesiology class, and the cause of hydrocephalus. Surgical details included whether the procedure was performed on an emergency or nonemergency basis, use of antibiotics, concurrent other surgical procedures, and the duration of surgical procedure. Details on shunt hardware included the type of shunt, the valve system, whether the shunt system included multiple or complex components, the type of distal catheter, site of the shunt, and side on which the shunt was placed.

Repeated shunt failures were assessed with multivariable time-to-event analysis (using the Cox regression model). Conditional models (as established by Prentice, et al.) were formulated for gap times (that is, times between successive shunt failures).

There were 1183 shunt failures in 839 patients. Failure time from the first shunt procedure was an important predictor for the second and third episodes of failures, thus establishing an association between the times to failure within individual patients. Age of less than 40 weeks gestation at time of the first shunt implantion carried a hazard ratio (HR) of 2.49 (95\% confidence interval [CI] 1.68-3.68) for the first failure and remained high for subsequent episodes of failure. Age of 40 weeks to 1 year (at the time of the initial surgery) also proved to be an important predictor of first shunt malfunctions (HR 1.77, 95\% CI 1.29-2.44). The cause of hydrocephalus was significantly associated with the risk of initial failure and, to a lesser extent, later failures. Concurrent other surgical procedures were associated with an increased risk of failure.

The patient's age at the time of initial shunt placement and the time interval since previous surgical revision are important predictors of repeated shunt failures in the multivariable model. Even after adjusting for age at first shunt insertion as well as the cause of hydrocephalus there is significant association between repeated failure times for individual patients.

Key Words * hydrocephalus * cerebrospinal fluid * cerebrospinal fluid shunt * ventriculoperitoneal shunt * prospective study 
Hydrocephalus remains an endemic condition in the pediatric population. With the advent of cerebrospinal fluid (CSF) diversionary procedures, there has been a decline in neurological deficit and death. However, CSF shunt failure is common, and the ratio of first shunt insertion to subsequent surgical revision is 1 to 2.5 in most centers.[40] Following initial shunt insertion, the failure rate by 1 year postimplantation is 25 to $40 \%$.[17] The 10 -year actuarial survival of a first CSF shunt is reported to be 30 to $37 \%$.[36, 40] Because these devices are usually required for the duration of the patient's life and in most cases there is more than one episode of shunt failure, performing repeated events analysis of CSF shunt failures is important.

In no study has there been a proper analysis of repeated shunt malfunction (and its relation to patient, hardware, and surgery-related characteristics). In some reports the investigators have either evaluated the first shunt failure or combined all the results of initial and repeated failures. However, because the repeated shunt failures are occurring in the same patients, they are not independent events and cannot be analyzed as such. We conducted a prospective observational study to identify risk factors predisposing to repeated CSF shunt malfunction and to determine whether subsequent shunt failures are related to earlier episodes of failure(s).

\section{CLINICAL MATERIAL AND METHODS}

\section{Data Collection}

A cohort study was conducted to evaluate the risk factors predisposing to repeated shunt failure. Data were collected on all patients who underwent their first shunt insertion between January 1, 1987 and December 31, 1996, and they were followed for at least 1 year (until December 31, 1997.) Data were collected prospectively from standardized forms filled out by the resident, fellow, or attending neurosurgeon for each shunt procedure (initial insertion and subsequent revisions). Data input was completed by a nonmedical data entry clerk. The information was audited for accuracy and completeness by an independent physician who was not on staff at the institution. Any discrepancy was settled by consultation with a staff neurosurgeon blinded to the case. Any patient whose medical records were missing was excluded.

The sample cases were obtained from the pediatric population (from birth to 18 years of age at the time of first shunt insertion) arriving at a tertiary care pediatric institution (The Hospital for Sick Children, in Toronto). A diagnosis of hydrocephalus (based on either ultrasound, computerized tomography scan, or magnetic resonance image) that required placement of a shunt was a prerequisite. Patients with hydrocephalus were grouped into categories based on cause: aqueductal stenosis, intraventricular hemorrhage (IVH), postmeningitic, myelominingocele, posttraumatic, tumor, congenital, and "other" (that is, cases that did not fit any of the proceeding categories). Any patient who had undergone a CSF shunt procedure at an outside institution was excluded (except for patients in whom continuous external ventricular drainage systems had been placed to treat their hydrocephalus). Patients without hydrocephalus who required a CSF shunt (for example, arachnoid cyst or pseudotumor cerebri) were also excluded.

Risk factors included those related to the patient characteristics, surgical details and shunt hardware. Data regarding patient age at the time of the first shunt insertion, patient gender, and cause of hydrocephalus were obtained from the prospectively collected procedural forms. Patient age was corrected for gestation. Measurement of the patient's head circumference (HC) was obtained from the medical records prior to each shunt procedure. In patients older than 2 years of age, these measurements were treated as missing values. If the shunt procedure involved removal of an external ventricular drainage and insertion of a shunt, the $\mathrm{HC}$ was not included, because the presence of the device and bandages were believed to provide an overestimate of the result. Each patient's weight was obtained from the anesthesia records for each shunt procedure. Surgical features included whether the procedure was performed on an emergency or nonemergency basis, the use of antibiotics, the duration of surgery, and whether any concurrent surgical procedure had been conducted. Data on the side on which the shunt was placed, its site, type (ventriculoperitoneal [VP] or other), valve type (differential pressure and flow regulated), and type of distal catheter (slit compared with open ended) were recorded. Information on whether multiple or complex shunts were in place was also noted. 


\section{Statistical Analysis}

The outcome of shunt failure was based on the patient's symptoms and signs, as well as pertinent diagnostic tests and intraoperative findings, in accordance with the guidelines established in the shunt design trial.[15] The outcome was similarly categorized as shunt obstruction, shunt infection, overdrainage, presence of loculated ventricles, and other. For each patient repeated shunt failures were identified and the risk factors determined.

Each shunt failure was indexed as a "failure level" (that is, 1, 2, 3, 4, and higher) according to whether it was the first, second, third, fourth episode of failure, and so on. Summary statistics were examined by failure level. Apparent differences in the mean values of continuous variables and distribution of categorical variables were examined. Estimates of the time to shunt failures were determined using the method of Lin, et al.[28] Spearman rank-order correlation coefficients were examined for $\mathrm{HC}$, age, and weight. We studied the occurrence of a given failure level by using a conditional Cox regression model,[9] as described in the report by Prentice, et al.[37] In the model that characterized the first episode of shunt failure all patients were included. Patients in whom shunt failure did not occur during the time of observation, including those who were lost to follow up or died of unrelated causes (censored), were not considered for the subsequent model of treatment failure (Fig. 1). For the second episode of failure, analyzsis was performed of only those patients who had experienced a first failure. Censored patients at this second shunt failure level were those in whom one failure had occurred and none subsequently. Thus, the kth failures were considered a risk set consisting of only those patients who had experienced k-1 failures (Fig. 1). The potential predictor variables for kth failures comprised of not only patient-related variables but also the time-to-failure characteristics for the $\mathbf{k}-\mathbf{1}$ preceding failures.

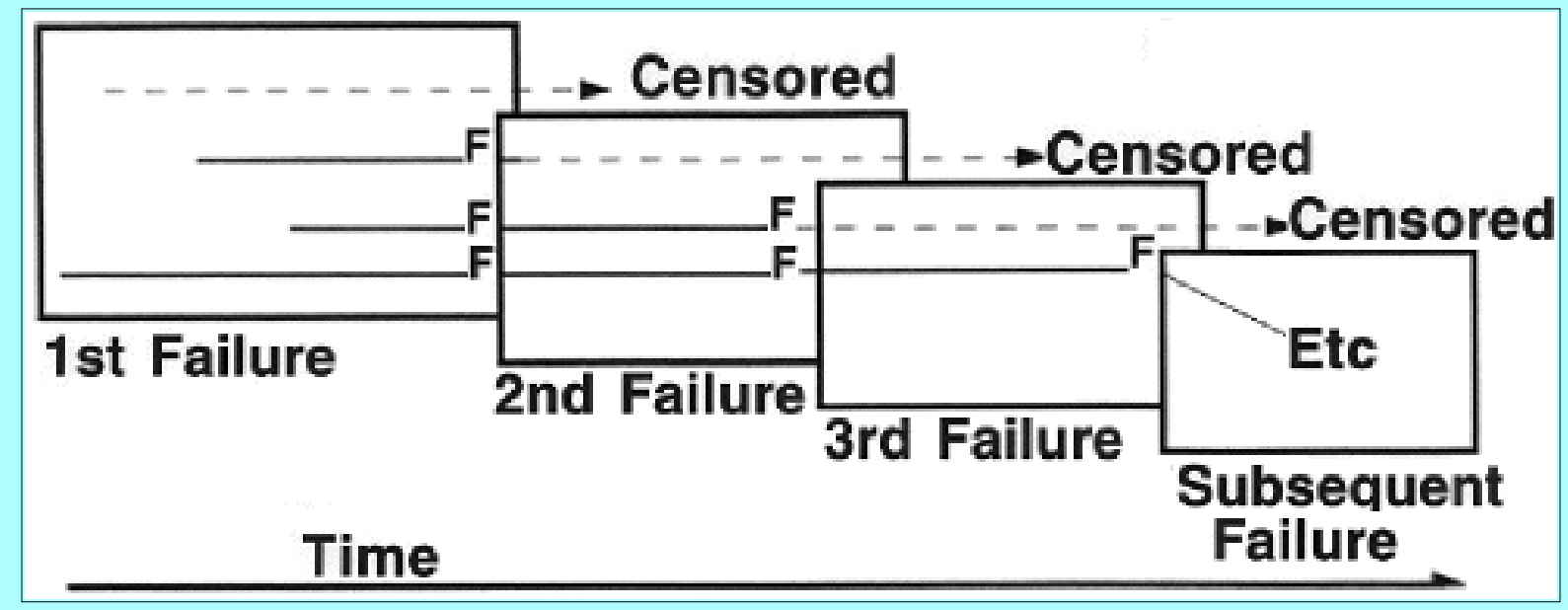

Fig. 1. Schematic drawing showing the level of CSF shunt failure. Analysis of each stage of failure evaluated the experience of only those patients in whom a shunt had previously failed, with the exception of the initial shunt failure. $F=$ failure.

We modeled the hazard ratios (HR) for time-to-failure characteristics for each new or revised shunting procedure based on the time from the last failure, termed the "gap time." Using "gap time" for second and subsequent failures, rather than time from initial shunt insertion, is important because the time of the second failure does not begin until after the first failure has occurred and because we wished to compare the times to failure of first and subsequent shunts. For this reason, we used the conditional approach described by Prentice, et al.,[37] as opposed to the marginal approach reported by Lin[27] and Wei, et al.,[45] or the counting process method of Andersen and Gill.[4]

First failure times were analyzed using the implementation of the Cox model provided by the "Splus" function "coxph." Based on single-factor models, which indicated the importance of age at first shunt insertion as well as the cause of hydrocephalus, we first determined the significance of these two risk factors in a model with three "age" and eight "cause" categories. We then considered whether other factors should be added, based on Wald and likelihood ratio tests, with significance set at the 0.05 level as a rough guideline.

We used a priori clinical judgment to categorize gestational-adjusted age at first surgery into the following groups: 
aged less than 40 weeks gestation; full term to 1 year; and older than 1 year. The reference category was chosen as that in which patients were greater than 1 year of age. When evaluating the eight causes of hydrocephalus, hydrocephalus associated with a congenital origin, which is commonly thought to constitute a low risk for shunt failure, was selected as the reference category. The factors of weight, $\mathrm{HC}$ and American Society of Anesthesiology (ASA) class entered the models as continuous variables. The time-to-failure variable for the preceding failure was categorized as less than 6 months and greater than or equal to 6 months. All surgery- and shunt-related characteristics were treated as categorical variables except for duration of surgery, which was continuous. Tied data were handled using the approximation method proposed by Breslow. The HR were calculated by exponentiating the regression coefficient, and 95\% confidence intervals (CIs) were computed. The final model was also assessed for significance of effect of modification due to age (of $<40$ weeks) and cause of hydrocephalus by incorporating into the model the interaction terms of age categories and the category of cause. Checks on the proportional-hazard models used for analysis were based on "Splus" implementation of martingale residuals, case influence plots, and an examination of time by covariate interaction. The statistical analysis was performed using the Statistical Analysis System (SAS Institute, Cary, NC) System Plus software and "Splus."

\section{RESULTS}

After excluding five patients for whom medical records were missing, the database contained 839 patients who experienced 1183 episodes of shunt failure. There were 46 patients in whom six or more failures were demonstrated, and the four largest numbers of failures experienced were 13,14, 15 and 30 (in one, two, one, and one patient, respectively). Because relatively few patients suffered more than three episodes of shunt failure, the analysis (related to patient characteristics) was restricted to the first three failure levels (Table 1). For the first failure level, the risk set comprised 839 patients; the second, 438; and the third, 241. In each level, shunt failure occurred in slightly more than half of the patients.

\begin{tabular}{|c|c|c|}
\hline \multirow[b]{3}{*}{ Shurt Failure } & \multicolumn{2}{|c|}{$\begin{array}{l}\text { TABLE } 1 \\
\text { VATONS MADE DURING EACH } \\
\text { OF SHUNT FAILURE }\end{array}$} \\
\hline & \multicolumn{2}{|c|}{ No. of Patierts } \\
\hline & Risk Set & Events \\
\hline $\begin{array}{l}1 \text { st } \\
\text { 2nd } \\
3 \text { rd }\end{array}$ & $\begin{array}{l}839 \\
438 \\
241\end{array}$ & $\begin{array}{l}453 \\
244 \\
142\end{array}$ \\
\hline
\end{tabular}

In Table 2 a summary of patient, shunt, and surgery-related characterisics are provided for patients who underwent one, two, and three shunt placement procedures. The mean gestational-adjusted age at the time of the first shunt insertion was 888.7 days; the median was 79 days. Slightly over half the patients were in the 40 weeks gestation to 1 year category. There were slightly more male patients in the study population across the different failure levels. As expected, the median weight increased across failure levels. The median $\mathrm{HC}$ increased from $39.5 \mathrm{~cm}$ in the first failure level to $42.5 \mathrm{~cm}$ by the third. The incidence of the most common homogenous causes of hydrocephalus in the initial risk set were myelomeningocele (22.8\%), tumor (22.6\%), and IVH (13.6\%). The proportion of IVH and postmeningitic cases increased and those of congenital- and tumor-related causes decreased as the number of failures increased. 
TABLE 2

PATENT, SURGERV, AND SHUNT-RELATED CHARACTER ITTKS*

\begin{tabular}{|c|c|c|c|c|c|}
\hline & & & & Int Fail ure Group & \\
\hline & Characteristic & & 1:st & 2nd & $3 r d$ \\
\hline no. of $p e$ & ients at risk & & 839 & 438 & 241 \\
\hline patient & $\begin{array}{l}\text { median age adjusted for gestatio } \\
\text { age }\end{array}$ & ays) & 79 & & \\
\hline & $\begin{array}{l}\quad<40 \text { wks gestation } \\
40 \text { wks gestation to } 1 \mathrm{yr} \\
>1 \mathrm{yr} \\
\text { female gender } \\
\text { median meight (range) } \mathrm{Kg} \\
\text { median } \mathrm{HC} \text { (range) on } \\
\text { cause of hudrocephalus }\end{array}$ & & $\begin{array}{c}139(16.6) \\
436(52.0) \\
264(31.5) \\
393(46.8) \\
5.4(11-107) \\
39.5(27-64)\end{array}$ & $\begin{array}{l}96(21.9) \\
242(55.3) \\
100(22.8) \\
217(49.5) \\
7.9(11-84.5) \\
41.9(31.5-58.5)\end{array}$ & $\begin{array}{r}62(25.7) \\
127(52.7) \\
52(21.6) \\
109(45.2) \\
9.4(2.1-100) \\
42.5(34-58.5)\end{array}$ \\
\hline & congenital & & $91(10.8)$ & $36(8.2)$ & $16(6.6)$ \\
\hline & $\begin{array}{l}\text { aqueductal stenosis } \\
\text { IVH }\end{array}$ & & $\begin{array}{c}56(6.7) \\
114(13.6)\end{array}$ & $\begin{array}{l}30(6.8) \\
73(16.7)\end{array}$ & $\begin{array}{l}12(5.0) \\
51(21.2)\end{array}$ \\
\hline & tumor & & $190(22.6)$ & $80(18.3)$ & $45(18.7)$ \\
\hline & posttraumatic & & $19(2.3)$ & $10(2.3)$ & $5(2.1)$ \\
\hline & m yelom eningocele & & $191(22.8)$ & $120(27.4)$ & $61(25.3)$ \\
\hline & postmeningitic & & $40(4.8)$ & $26(5.9)$ & $19(7.9)$ \\
\hline & $\begin{array}{c}\text { other } \\
\text { mean } A \text { SA class (SD) }\end{array}$ & & $\begin{array}{l}138(16.4) \\
2.6(0.82)\end{array}$ & $\begin{array}{l}63(14.4) \\
2.6(0.78)\end{array}$ & $\begin{array}{l}32(13.3) \\
2.7(0.77)\end{array}$ \\
\hline surgical & emergency surgery & yes & $96(11.4)$ & $63(14.4)$ & $43(17.8)$ \\
\hline & & no & $546(65.1)$ & $298(68.0)$ & $160(66.4)$ \\
\hline & prophyactc anticiotic use & yes & $670(19.9)$ & $\begin{array}{l}38187.0) \\
57(130)\end{array}$ & $204(84.6)$ \\
\hline & concurrent nonshunt procedure & yes & $75(8.9)$ & $26(5.9)$ & $13(5.4)$ \\
\hline & & no & $764(91.1)$ & $412(94.1)$ & $228(94.6)$ \\
\hline & median duration (range) in mins & & $65(10-440)$ & $65(15-365)$ & $65(10-325)$ \\
\hline shunt & shunt site & frontal & $103(12.3)$ & $57(13.0)$ & $37(15.4)$ \\
\hline & shunt side & left onl $y$ & $363(43.3)$ & $199(45.4)$ & $113(46.9)$ \\
\hline & & right only & $436(52.0)$ & $220(50.2)$ & $113(46.9)$ \\
\hline & shunt type & WP & $763(90.9)$ & $400(91.3)$ & $216(89.6)$ \\
\hline & & other & $76(9.1)$ & $38(8.7)$ & $25(10.4)$ \\
\hline & val we type & flow regulated & $81(9.7)$ & $6(1.4)$ & $3(1.2)$ \\
\hline & & diff & $721(85.9)$ & $402(91.8)$ & $225(93.4)$ \\
\hline & distal catheter & slit & $405(48.3)$ & $200(45.7)$ & $114(47.3)$ \\
\hline & & open & $284(33.8)$ & $144(32.9)$ & $69(28.6)$ \\
\hline & multiple shunts & yes & $2(0.2)$ & $44(10.0)$ & $55(22.8)$ \\
\hline & & no & $837(99.8)$ & $394(90.0)$ & $186(77.2)$ \\
\hline & complex shunt & yes & $3(0.4)$ & $18(4.1)$ & $12(5.0)$ \\
\hline & & no & $836(99.6)$ & $420(95.9)$ & $229(95.0)$ \\
\hline
\end{tabular}

" Unless otherwise noted, all walues represent the num ber of patients (\%) in whom any gi ven characteristic was present. Ábbre viations: diff pressure = differential pressure; $\mathrm{SD}=$ standard de viation.

There was high intercorrelation, in the first failure level, between age and weight $\left(\mathrm{r}_{\mathrm{s}}=0.95\right)$, age and $\mathrm{HC}\left(\mathrm{r}_{\mathrm{s}}=\right.$ $0.74)$, and weight and $\mathrm{HC}\left(\mathrm{r}_{\mathrm{s}}=0.86\right)$. Because age is the most objective measure among these three variables, only the age variable was entered into the regression models.

With respect to the surgical procedure 11.4 to $17.8 \%$ of the cases were treated on an emergency basis, depending on the failure level. Prophylactic antibiotic drugs were used in $79.9 \%$ of the cases, and 5.4 to $8.9 \%$ (ranging from first to third failure level) of the patients in whom shunts were placed underwent a concurrent nonshunt procedure. The median duration of the procedures was 65 minutes.

The VP shunt was used in over $90 \%$ of the cases, and differential pressure valves were used in 85.9 to $93.4 \%$ of the cases depending on the failure group analyzed. The occipital burr hole was the most common site, with the shunt placed equally on both sides. The proportion of cases in which we used a distal slit-valve catheter was slightly greater than those in which an open-ended valve catheter was used. Of cases in which the shunt had failed up to three times, in $22.8 \%$ multiple shunts and in 5\% a complex system were used. 
Of the complications demonstrated in those patients in whom the shunt failed a single time, obstruction occurred in $66.7 \%$, infection in $19 \%$, overdrainage in $5.7 \%$, and loculated ventricles in $7.7 \%$ of the cases (Table 3). As the number of shunt-failure episodes increased, the proportion of cases in which obstruction occurred increased, and those of infection and overdrainage decreased and that of loculated ventricles remained approximately the same.

\begin{tabular}{|c|c|c|c|}
\hline \multirow[b]{3}{*}{ Cause of Failure } & \multicolumn{3}{|c|}{$\begin{array}{l}\text { TABLE } 3 \\
\text { ATIENTS WHO UNDERWENT ONE, TWO, AND } \\
\text { IMPLANTATION PROCEDURES }\end{array}$} \\
\hline & \multicolumn{3}{|c|}{ Failure Group (\%) } \\
\hline & 13t & 2nd & $3 r d$ \\
\hline $\begin{array}{l}\text { infection } \\
\text { obstruction } \\
\text { owerdrainage } \\
\text { loculated wenticles } \\
\text { other }\end{array}$ & $\begin{array}{c}86(19.0) \\
302(66.7) \\
26(5.7) \\
35(7.7) \\
4(0.1)\end{array}$ & $\begin{array}{c}35(14.3) \\
181(74.2) \\
5(2.0) \\
22(9.0) \\
1(0.4)\end{array}$ & $\begin{array}{c}14(9.9) \\
110(77.5) \\
3(2.1) \\
12(8.5) \\
3(0.7)\end{array}$ \\
\hline
\end{tabular}

Figure 2 shows the survival curves determined for patients in whom shunting failed one, two, three, or four times. In determining these estimates we did not make adjustments for age, cause of hydrocephalus, or other risk factors across patients, and the differing distribution of risk factors for different failure levels makes comparison difficult. In addition, limitations on the total length of follow-up review made it necessary to restrict attention to the second, third, and fourth episodes of shunt failure in patients whose preceding failures all occurred within 3000 days. As the results shown in Fig. 2 suggest, the survival distributions for the first, second, and third episodes of shunt failure are comparable over the first 1000 days but the fourth failure times tend to be shorter. However, because the estimated distribution of fourth failures is effectively based on only 137 patients, it is rather imprecise.

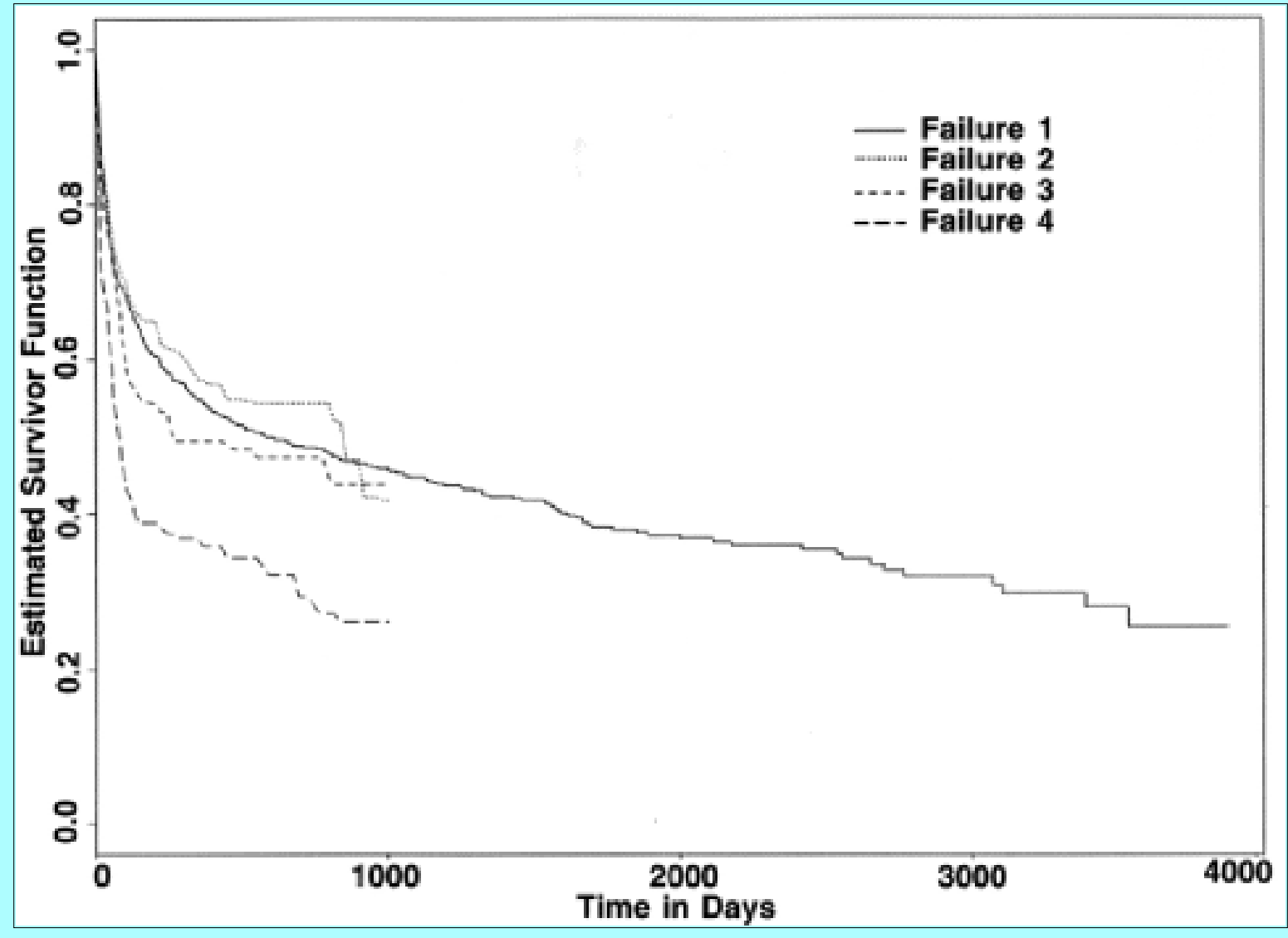

Fig. 2. Graph demonstrating survival curves for patients in whom shunting failed one, two, three, or four times.

Results of the multivariable analysis for sequential failure are described below. As predictors of the first episode of 
failure, age and certain causes of hydrochephalus were statistically significant (Table 4). Age less than 40 weeks at the first shunt insertion carried an HR of 2.49 (95\% CI 1.68-3.68; $\mathrm{p}<0.0001$ ), whereas age between 40 weeks and 1 year had a lower HR (1.77; CI 1.29-2.44; $\mathrm{p}=0.0005)$. Of the noncongenital-related causes of hydrocephalus, the presence of trauma had the highest HR relative to congenital $(2.80 ;$ CI 1.39-5.64; $p=0.004)$. This was followed by the presence of tumor with an HR of 2.33 (CI 1.48-3.68; $\mathrm{p}=0.0003$ ), postmeningitic with an HR of 2.08 (CI 1.26-3.44; $\mathrm{p}=0.004$ ), myelomeningocele with an HR of 1.95 (CI 1.34-2.85; $\mathrm{p}=0.0005)$, and intraventricular hemorrhage with HR of 1.78 (CI 1.18-2.68; $\mathrm{p}=0.006$ ). Ventriculoperitoneal shunts carried a lower risk of failure compared with all other types (HR 0.69, CI 0.50-0.95; $\mathrm{P}=0.024$ ), and the presence of concurrent nonshunt related procedure was associated with a higher risk of failure (HR 1.44, CI 1.06-1.94; $\mathrm{P}=0.02)$.

\begin{tabular}{|c|c|c|c|c|c|c|c|c|c|}
\hline \multirow[b]{4}{*}{ Risk Fact or } & \multicolumn{8}{|c|}{$\begin{array}{l}\text { TABLE } 4 \\
\text { P YALUES O }\end{array}$} & \\
\hline & \multicolumn{8}{|c|}{ Failure Group } & \\
\hline & \multicolumn{3}{|c|}{ 1st } & \multicolumn{3}{|c|}{ 2nd } & \multicolumn{3}{|c|}{$\overline{3 r d}$} \\
\hline & $\mathrm{HR}$ & $\frac{95 \%}{\mathrm{Cl}}$ & val ue & $\mathrm{HR}$ & $\stackrel{95 \%}{\mathrm{Cl}}$ & $\mathrm{val}$ ue & $\mathrm{HR}$ & $\frac{95 \%}{\mathrm{Cl}}$ & val ue \\
\hline gap time of previous failure & & & & 1.72 & $1.28-2.30$ & $<0.001$ & 1.50 & $1.05-2.16$ & 0.027 \\
\hline $\begin{array}{l}<40 \text { wiks } \\
40 \text { wiks to } 1 \text { yr } \\
\text { cause of hydrocephalus } t\end{array}$ & $\begin{array}{l}2.49 \\
1.77\end{array}$ & $\begin{array}{l}1.68-3.68 \\
1.29-2.44\end{array}$ & $\begin{array}{l}<0.001 \\
<0.001\end{array}$ & $\begin{array}{l}1.59 \\
1.33\end{array}$ & $\begin{array}{l}0.93-2.74 \\
0.84-2.11\end{array}$ & $\begin{array}{l}0.096 \\
0.22\end{array}$ & $\begin{array}{l}1.71 \\
0.90\end{array}$ & $\begin{array}{l}1.05-2.79 \\
0.57-1.42\end{array}$ & $\begin{array}{l}0.032 \\
0.65\end{array}$ \\
\hline $\begin{array}{l}\text { aqueductal stenosis } \\
\text { IVH } \\
\text { postmeningitic } \\
\text { m yelom eningocele } \\
\text { posttraumatic } \\
\text { tumor } \\
\text { other } \\
\text { WP com pared with other } \\
\text { shunt type }\end{array}$ & $\begin{array}{l}1.83 \\
1.78 \\
2.08 \\
1.95 \\
2.80 \\
2.33 \\
1.56 \\
0.69\end{array}$ & $\begin{array}{l}1.13-2.96 \\
1.18-2.68 \\
1.26-3.44 \\
1.34-2.85 \\
1.39-5.64 \\
1.48-3.68 \\
1.03-2.35 \\
0.50-0.95\end{array}$ & $\begin{array}{l}0.01 \\
0.006 \\
0.004 \\
0.001 \\
<0.004 \\
<0.001 \\
0.03 \\
0.02\end{array}$ & $\begin{array}{l}0.77 \\
1.85 \\
2.32 \\
1.10 \\
1.86 \\
2.34 \\
1.31\end{array}$ & $\begin{array}{l}0.36-1.64 \\
1.03-3.33 \\
1.19-4.54 \\
0.63-1.92 \\
0.67-5.18 \\
1.22-4.48 \\
0.72-2.39 \\
\text { NS }\end{array}$ & $\begin{array}{l}0.50 \\
0.039 \\
0.014 \\
0.74 \\
0.23 \\
0.01 \\
0.38\end{array}$ & & NS & \\
\hline concurrent surgery & 1.44 & $1.06-1.94$ & 0.02 & & NS & & 1.89 & $1.01-3.53$ & 0.047 \\
\hline
\end{tabular}

For the group of patients in whom shunting failed a second time, the dichotomized time-to-first-failure variable $(<$ or $>6$ months) had an HR of 1.70 (CI 1.28-2.30; p = 0.0004). Intraventricular hemorrhage myelomeningocele, and tumor were also statistically significant, whereas patient age at the first surgery was not (see Table 4). For those in whom shunting failed a third time, a similarly dichotomized gap time of the previous (second) shunt failure, age of less than 40 weeks gestation (at the time of initial shunt insertion), and concurrent nonshunt-related procedure were found significant at the $\mathrm{p}<0.05$ level.

Neither the gender, ASA class, emergency surgery, use of prophylactic antibiotics, duration of surgery, or any of the shunt-related factors (except shunt type) was found to be statistically significant in terms of being associated with shunt failures (see Table 5 for the first failures). There was no evidence that the association between shunt malfunction and type of hydrocephalic cause varied by age category (that is, there was no evidence of effect modification). With respect to assessment of the proportional-hazard assumption, no substantial departures from the model assumptions were found. 


\section{TABLE 5}

CONF DENCE INTERYALS AND P YALUES FOR YARMBLES IN THE FIRST SHUNT

FAILURE GROUP THAT WERE NOT INCLUDED IN THE FINAL MODEL*

\begin{tabular}{llc}
\hline \hline \multicolumn{1}{c}{ RISK FACTOR } & $95 \% \mathrm{Cl}$ & P V ALUE \\
\hline gender & $0.90-1.31$ & 0.41 \\
ASA class & & 0.13 \\
emergency surgery & $0.81-1.45$ & 0.61 \\
prophylactic anti tiotic use & $0.71-1.11$ & 0.30 \\
duration of surgery (in ins) & & 0.96 \\
shunt site (oocipital) & $0.84-1.63$ & 0.35 \\
shunt side (eft) & $0.89-1.30$ & 0.45 \\
valve type (flow regulated) & $0.79-1.58$ & 0.52 \\
distal catheter (open) & $0.93-1.43$ & 0.19 \\
\hline
\end{tabular}

$\approx$ These variables were not in duded in the final model because they were not significant. Note that the variables "multiple" and "complex" mere not e valuated for the first shunt failure episode due to the paucity of events.

\section{DISCUSSION}

All neurosurgeons struggle with CSF shunt failure, and most have had professional experiences that lead them to suspect that particular subgroups of patients, types of shunt equipment, or surgical techniques may be the culprits. Identification of risk factors, however, has been difficult because of the requirement of a large population of patients, who are required to undergo follow-up review for a considerable length of time and whose data must be analyzed by quite sophisticated statistical techniques, which have only recently been made widely available. $[4,37,45]$ In a number of previous studies the authors have evaluated risk factors contributing to shunt malfunction. These studies have essentially been descriptive or observational in nature, and interventional studies have been rare. Since 1980, there have been 38 studies published in the English literature on CSF diversionary procedures in children (with exclusion of studies related to the value of antibiotic use).[1-3,5-8,10-14,16,18-26,29-36,38-44,46] There have been 20 analytical studies, and 18 descriptive studies. Reference to multiple shunt failures, particularly in relation to patient characteristics, has rarely been made.

In this study we were able to accrue a sufficiently large group of patients over a long enough time period to apply these statistical techniques. The results, however, are somewhat dismaying in that none of the easily remedial factors, such as shunt-valve design, shunt implantation site, length of surgery, and use of antibiotics, appeared to be of any significance. Instead unchangeable patient characteristics such as age as well as the cause of hydrocephalus were found to be significant. We think that this is extremely important information, however, because it may prevent investigators from pursuing treatment strategies that are unlikely to have any effect. This finding also can be used to identify those patients at highest risk who might benefit most from any effective change in practice.

Perhaps the most interesting finding of the study is that the length of time from the previous shunt failure is an important risk factor for subsequent shunt failure, even accounting for other patient, shunt, and surgical factors. The HR for the second and third episodes of shunt failure was approximately 1.5 times for shunts that failed within 6 months compared with those that failed after 6 months. The contribution of this factor remains essentially unchanged as the failure level increased, suggesting that the timing of a previous procedure is a fundamental component of repeated shunt malfunctions.

Piatt[35] Piatt and Carlson[36] also noted an increased risk of failure for shunts that undergo revision in less than 6 months since implantation, although they failed to separate new from revised shunts and did not provide a multivariable analysis. We further support this finding. The really interesting question is why does this increase in failure risk occur? We were not able to demonstrate that infection leads to this occurrence, but rather that it seems to be a general response to a shunt revision. It seems reasonable that the trauma of shunt revision, and perhaps the reaction of the ventricular tissue, may incite an inflammatory response that predisposes to subsequent shunt obstruction. This suggests that more inert shunt materials, or even antiinflammatory medication, might reduce repeated shunt failure. 
In terms of "survival" analysis of shunt failure, Cozzens and Chandler[10] have alluded to a finding of decreasing time to failure for recurrent shunt failure, but they failed to elucidate the manner in which categorization in risk sets was achieved; in addition, they pooled new shunt replacement procedures with revisions. In a more recent paper by Lazareff, et al.,[26] similar findings with the same problematic type of analysis were demonstrated. These earlier studies have suggested a trend in shorter failure times as the number of episodes of shunt failure increases, but these conclusions were based on analysis that ignored the association between successive failure times; this tends to impact the estimates of the higher level failure distribution downwards. Our analysis accounts for this association and does not show a marked trend, although the possibility that the fourth failure times tend to be shorter is indicated.

It is perhaps no surprise that age is a risk factor for shunt failure. The role of age at the time of first shunt insertion has been evaluated previously in several observational studies.[7, 10, 13, 29, 30, 35, 36] In the Cooperative Survey of the 1991 to 1992 education committee of the International Society of Pediatric Neurosurgeons (ISPN) the role of age was evaluated only in first shunts insertions, and the authors noted that there was a higher rate of failure among patients in whom shunt implantations were performed at less than 6 months of age.[13] However, in a retrospective study of 170 hydocephalic patients with myelomeningocele, no statistically significant difference in risk of failure was demonstrated in those patients undergoing a first placement procedure at less than and greater than one week of age.[7] In our study we corrected for gestational age, and our results indicate that age at the time of first shunt insertion proved to be an important contributor not only to the first failure but also to the subsequent failure levels analyzed. Patients aged less than 40 weeks and between 40 weeks to 1 year of age had an HR of 2.49 and 1.77, respectively (in comparison with shunt insertions performed in patients greater than 1 year of age). That prematurity at first shunt insertion would presidispose to subsequent shunt revisions is again a fascinating finding, which may lend further support that some fundamental tissue reaction occurs in response to shunt insertion.

Weight and $\mathrm{HC}$ are clearly age-related factors in this patient population. It has been reported that, according to univariate analysis, patients who weighed less than $3000 \mathrm{~g}$ had no statistically significant difference in the rate of infection, and there was a barely significant $(\mathrm{p}=0.05)$ worse overall shunt survival rate among patients weighing less than 3000 g. [30] In 67 patients with neural tube defects, who underwent a total of 122 shunt procedures, HC at the time of shunt insertion did not correlate with shunt survival.[29] We thought that age was a better indication of patient maturity,.because age was so highly correlated with weight and $\mathrm{HC}$, and particularly HC may be influenced by the extent of hydrocephalus.

Much controversy surrounds the effect of cause of hydrocephalus on multiple shunt failures. In a number of studies the authors have addressed this issue, $[8,10,13,18,20,30,35,36,42,44]$ although its role in repeated failures has not been evaluated. Three reports have suggested that IVH,[10] tumor,[42] and neural tube defects[30] appear as significant contributors to shunt failure, whereas in three others, causation did not appear to play a role.[18, 35, 36] In reports in which only initial insertions were evaluated, IVH appeared as a causative factor.[13, 20] In one the authors reported on a homogenous population of patients in whom only distal double slit-valve systems were placed[20] whereas the International Society of Pediatric Neurosurgeons study excluded neoplastic cases.[13] Our findings revealed that $\mathrm{IVH}$, postmeningitis, and tumor were significant causative factors in the first and second episodes of shunt failure, all with similar CIs.

Concurrent surgical procedure was noted to increase the risk of shunt failure. Most neurosurgeons try to implant shunts in the setting of a single procedure, but occasionally, particularly in the setting of patients with tumors requiring a biopsy, this is difficult. This group may simply be at increased risk of a subsequent shunt failure. In comparison with other shunt types (lumboperitoneal or ventriculoatrial) VP shunts had a lower risk of failure, but the hydrocephalus in these patients may be significantly different, making assessment of this finding difficult.

Cerebrospinal fluid shunt failure is similar to many other conditions in which repeated events occur in the same patient (such as tumor recurrence, recurrent lumbar disc disease, or recurrent tic douloureux pain). To account for multiple observations obtained in the same individual is stastistically important because, otherwise, underestimation of the standard error, with the improper finding statistical significance, occurs where none exists. In many of the 
aforementioned studies the authors have failed to account for this problem.[7,10,13,18,29,30,35,36,40,44] There have been a few methods used to evaluate repeated events for time to failure outcomes, two of which include the marginal method used by Wei, et al.,[45] and the counting process approach described by Andersen and Gill.[4] An additional method proposed by Preutice, et al.,[37] addresses the issue of a conditional approach, which appears most appropriate with regards to repeated episodes of failure in CSF shunt cases. This method allows dependence among repeated failure times to be explicitly addressed. This is the technique we have used in this study, which we think is most likely to find true risk factor effects.

In conclusion, the timing of the previous shunt procedure is significant: a revision performed in less than 6 months results in an increased risk of failure. This also establishes that there is a significant association between repeated CSF shunt failure times in a given individual. Age at first shunt insertion and time interval since last revision are the more important patient-related predictors of repeated shunt failures in the multivariable model. Concurrent surgical intervention was associated with an increased risk of shunt-related failure, yet none of the other shunt characteristics or surgery-related features reached statistical significance. Recurrent CSF shunt failure remains a fascinating problem worthy of our best efforts.

\section{References}

1. Albright AL, Haines SJ, Taylor FH: Function of parietal and frontal shunts in childhood hydrocephalus. J Neurosurg 69:883-886, 1988

2. Aldrich EF, Harmann P: Disconnection as a cause of ventriculoperitoneal shunt malfunction in multicomponent shunt systems. Pediatr Neurosurg 16:309-312, 1990/91

3. Amacher AL, Wellington J: Infantile hydrocephalus: long-term results of surgical therapy. Childs Brain 11:217-229, 1984

4. Andersen PK, Gill RD: Cox's regression model for counting processes: A large sample study. Ann Stat 10:1100-1120, 1982

5. Bierbrauer KS, Storrs BB, McLone DG, et al: A prospective, randomized study of shunt function and infections as a function of shunt placement. Pediatr Neurosurg 16:287-291, 1990/91

6. Borgbjerg BM, Gjerris F, Albeck MJ, et al: Frequency and causes of shunt revisions in different cerebrospinal fluid shunt types. Acta Neurochir 136:189-194, 1995

7. Caldarelli M, Di Rocco C, La Marca F: Shunt complications in the first postoperative year in children with meningomyelocele. Childs Nerv Syst 12:748-754, 1996

8. Choudhury AR: Avoidable factors that contribute to the complications of ventriculoperitoneal shunt in childhood hydrocephalus. Childs Nerv Syst 6:346-349, 1990

9. Cox DR: Regression models and life tables. J R Stat Soc (B) 34:187-202, 1972

10. Cozzens JW, Chandler JP: Increased risk of distal ventriculoperitoneal shunt obstruction associated with slit valves or distal slits in the peritoneal catheter. J Neurosurg 87:682-686, 1997

11. da Silva MC, Drake JM: Complications of cerebrospinal fluid shunt antisiphon devices. Pediatr Neurosurg 17:304-309, 1991/92

12. Di Rocco C, Mancinelli R, Pola P, et al: A modified slit-valve shunt prototype for the management of hydrocephalus. J Neurosurg 54:763-766, 1981

13. Di Rocco C, Marchese E, Velardi F: A survey of the first complication of newly implanted CSF shunt devices for the treatment of nontumoral hydrocephalus. Childs Nerv Syst 10:321-327, 1994 
14. Drake JM, da Silva MC, Rutka JT: Functional obstruction of an antisiphon device by raised tissue capsule pressure. Neurosurgery 32:137-139, 1993

15. Drake JM, Kestle J: Rationale and methodology of the multicenter pediatric cerebrospinal fluid shunt design trial. Pediatric Hydrocephalus Treatment Evaluation Group. Childs Nerv Syst 12:434-447, 1996

16. Drake JM, Kestle JRW, Milner R, et al: Randomized trial of cerebrospinal fluid shunt valve design in pediatric hydrocephalus. Neurosurgery 43:294-305, 1998

17. Drake JM, Sainte-Rose C: The Shunt Book. Cambridge, MA: Blackwell Science, 1995, pp 123-192

18. Griebel R, Khan M, Tan L: CSF shunt complications: an analysis of contributory factors. Childs Nerv Syst 1:77-80, 1985

19. Gruber R, Jenny P, Herzog B: Experiences with the anti-siphon device (ASD) in shunt therapy of pediatric hydrocephalus. J Neurosurg 61:156-162, 1984

20. Hahn YS: Use of the distal double-slit valve system in children with hydocephalus. Childs Nerv Syst 10:99-103, 1994

21. Hayden PW, Shurtleff DB, Stuntz TJ: A longitudinal study of shunt function in 360 patients with hydrocephalus. Dev Med Child Neurol 25:334-337, 1983

22. Hoffman HJ, Hendrick EB, Humphreys RP: Experience with ventriculo-pleural shunts. Childs Brain 10:404-413, 1983

23. James HE, Bejar R, Gluck L, et al: Ventriculoperitoneal shunts in high risk newborns weighing under 2000 grams: a clinical report. Neurosurgery 15:198-202, 1984

24. Jones RFC, Currie BG, Kwok BCT: Ventriculopleural shunts for hydrocephalus: a useful alternative.

Neurosurgery 23:753-755, 1988

25. Kast J, Duong D, Nowzari F, et al: Time-related patterns of ventricular shunt failure. Childs Nerv Syst 10:524-528, 1994

26. Lazareff JA, Peacock W, Holly L, et al: Multiple shunt failures: an analysis of relevant factors. Childs Nerv Syst 14:271-275, 1998

27. Lin DY: MULCOX: a computer program for the Cox regression analysis of multiple failure time variables. Comput Methods Progr Biomed 32:125-135, 1990

28. Lin DY, Sun W, Ying Z: Nonparametric estimation of the gap time distributions for serial events with censored data. Biometrika 86:59-70, 1999

29. Liptak GS, Masiulis BS, McDonald JV: Ventricular shunt survival in children with neural tube defects. Acta Neurochir 74:113-117, 1985

30. Liptak GS, McDonald JV: Ventriculoperitoneal shunts in children: factors affecting shunt survival. Pediatr Neurosci 12:289-293, 1985/86

31. Mazza C, Pasqualin A, Da Pian R: Results of treatment with ventriculoatrial and ventriculoperitoneal shunt in infantile nontumoral hydrocephalus. Childs Brain 7:1-14, 1980

32. McCullough DC: Symptomatic progressive ventriculomegaly in hydrocephalics with patent shunts and antisiphon devices. Neurosurgery 19:617-621, 1986

33. Olsen L, Frykberg T: Complications in the treatment of hydrocephalus in children. A comparison of 
ventriculoatrial and ventriculoperitoneal shunts in a 20-year material. Acta Pediatr Scand 72:385-390, 1983

34. Pezzotta S, Locatelli D, Bonfanti N, et al: Shunt in high-risk newborns. Childs Nerv Syst 3:114-116, 1987

35. Piatt JH Jr: Cerebrospinal fluid shunt failure: late is different from early. Pediatr Neurosurg 23:133-139, 1995

36. Piatt JH Jr, Carlson CV: A search for determinants of cerebrospinal fluid shunt survival: retrospective analysis of a 14-year institutional experience. Pediatr Neurosurg 19:233-242, 1993

37. Prentice RL, Williams BJ, Peterson AV: On the regression analysis of multivariate failure time data.

Biometrika 68:373-379, 1981

38. Sainte-Rose C: Shunt obstruction: a preventable complication? Pediatr Neurosurg 19:156-164, 1993

39. Sainte-Rose C, Hooven MD, Hirsch JF: A new approach in the treatment of hydrocephalus. J Neurosurg 66:213-226, 1987

40. Sainte-Rose C, Piatt JH, Renier D, et al: Mechanical complications in shunts. Pediatr Neurosurg 17:2-9, $1991 / 92$

41. Serlo W: Experiences with flow-regulated shunts (Orbis-Sigma valves) in cases of difficulty in managing hydrocephalus in children. Childs Nerv Syst 11:166-169, 1995

42. Serlo W, Fernell E, Heikkinen E, et al: Functions and complications of shunts in different etiologies of childhood hydrocephalus. Childs Nerv Syst 6:92-94, 1990

43. Serlo W, von Wendt L, Heikkinen ES, et al: Ball and spring or slit and core valve for hydrocephalus shunting? Ann Clin Res 47 (Suppl 18): 103-106, 1986

44. Valentini L, Solero CL, Lasio G, et al: Triventricular hydrocephalus: review of 71 cases evaluated at the Istituto Neurologico "C. Besta" Milan over the last 10 years. Childs Nerv Syst 11:170-172, 1995

45. Wei LJ, Lin DY, Weissfeld L: Regression analysis of multivariate incomplete failure time data by modeling marginal distributions. J Am Stat Assoc 84:1065-1073, 1989

46. Wiedemayer H, Sackers S: Clinical experience with a new flow-regulating hydrocephalus shunt system. Adv Neurosurg 21:151-155, 1993

Manuscript received August 9, 1999.

Accepted in final form September 2, 1999.

Address reprint requests to: James Drake, M.B., B.Ch., The Hospital for Sick Children, 555 University Avenue, Toronto, Ontario, Canada, M5G 1X8. 